\title{
A Institucionalização do Ensino a Distância no Brasil: o caso da Graduação em Administração na Universidade Federal do Rio Grande do Norte (UFRN)
}

\author{
Sueli Menelau de Novais ${ }^{1}$ \\ Antônio Sérgio Araújo Fernandes ${ }^{2}$
}

\section{Resumo}

O Ensino a Distancia (EaD) tem no projeto do Curso Piloto de Administração uma importante iniciativa para sua difusão no país. Esse projeto se configura em um consórcio de 25 Instituições de Ensino Superior (IES), apoiado pelo MEC, pela Universidade Aberta do Brasil (UAB) e pelo Banco do Brasil (BB). Este trabalho procura compreender o processo de institucionalização deste na UFRN, identificando as principais ações isomórficas com vistas à sua legitimação. Adotouse a pesquisa qualitativa, ainda que tenham sido adicionadas técnicas estatísticas como survey, Anova de $\mathrm{N}$ fatores e o teste de Tuckey. A pesquisa apontou que as IES que atuam com EaD ainda não constituem um campo organizacional e a criação, bem como o estabelecimento do Curso no contexto da UFRN foram advindos de pressões isomórficas externas, porém apenas as variáveis internas influenciam positivamente à institucionalização do Curso.

Palavras-chave: Institucionalização. Ensino a Distância. Curso de Administração.

\section{Introdução}

Por toda a parte o Ensino a Distância $(\mathrm{EaD})$ vem despontando não apenas como um campo peculiar de um segmento com potencialidade global,

\footnotetext{
${ }^{1}$ Doutoranda em Administração pela Universidade de Brasília - UnB. Endereço: Universidade Federal do Rio Grande do Norte, Centro de Ciências Sociais Aplicadas, Programa de Pós-Graduação em Administração (PPGA). End.: Av. Senador Salgador Filho, s/n - Lagoa Nova, Natal-RN. CEP: 59072-970-Brasil.E-mail: suelimenelau@yahoo.com.br.

${ }^{2}$ Doutor em Ciência Política pela Universidade de São Paulo-USP. Atualmente é professor adjunto da Universidade Federal do Rio Grande do Norte - UFRN no Programa de Pós-Graduação em Administração. End.: Universidade Federal do Rio Grande do Norte, Centro de Ciências Sociais Aplicadas, Programa de Pós-Graduação em Administração (PPGA). Av. Senador Salgador Filho, s/n - Lagoa Nova, Natal - RN CEP: 59072-970 - Brasil.E-mail: asaferna@uol.com.br.

Artigo recebido em: 05/08/2010. Aceito em: 22/11/2010. Membro do Corpo Editorial Científico responsável pelo processo editorial: Gilberto de Oliveira Moritz.

(c) (i) $\Theta$ Esta obra está sob a Licença Creative Commons Atribuição-Uso.
} 
mas também, como uma modalidade que transcende a utilização da metodologia, com possibilidade de alcançar grandes contingentes populacionais, em proporções exponenciais. $\mathrm{O}$ uso intensivo das Tecnologias de Informação e Comunicação (TICs) permite aplicabilidade e monitorização do processo de ensino-aprendizagem, de forma abrangente, como nunca antes vivenciada. Nesse contexto, buscando consolidar a modalidade no país, foi criado em 2005 e oficializado em 2006 com o Decreto n. 5.800 - pelo Ministério da Educação e Cultura (MEC), por meio do Fórum das Estatais pela Educação (composto pela Universidade Virtual do Brasil e a Associação Nacional dos Dirigentes das Instituições Federais de Ensino Superior), o Sistema Universidade Aberta do Brasil (UAB). Principal aposta do Governo Federal no intuito de democratizar o ensino superior brasileiro, a UAB tem como meta ser um Sistema fundamentado no aprendizado pela internet, o $e$ Learning, para proporcionar graduação a professores e estudantes de localidades que não possuem Instituições de Ensino Superior Públicas (IESP), visando oferecer graduação gratuita aos 5.561 municípios brasileiros, permitindo que as 55 Universidades Federais e os 30 Institutos Federais de Educação, Ciência e Tecnologia garantam o ensino em todo o território (CAPES/ UAB, 2007).

É nessa realidade que as IESP se deparam com desafios a serem superados, pois, se por um lado as TICs vêm promovendo um re-encantamento ao processo, por outro, são relatadas dificuldades relacionadas ao seu uso e controvérsias quanto ao seu reconhecimento, fatores que demonstram que o EaD no Brasil ainda não é uma prática institucionalizada. Ao analisar os impactos da metodologia no meio acadêmico, Belloni (2003, p. 15) comenta sobre as peculiaridades do contexto educacional enfocando que "[...] o campo da educação é extremamente complexo e altamente resistente à mudança”. Essa afirmação encerra uma reflexão sobre o papel das IESP na contemporaneidade, pois a evolução do sistema educativo, como consequência do desenvolvimento da sociedade, resultante de uma adaptação inevitável das pressões exteriores do ambiente social, político e cultural do qual faz parte, leva seu ambiente interno a ter o domínio ampliado para fora dos limites físicos, redefinindo papeis, tendo em vista que o ensino é também processado aquém e além de limites dos muros.

No contexto dos estudos organizacionais, uma das teorias que aborda a adaptação das organizações frente às mudanças e transformações é a Teoria Institucional (TI). Ela procura explicar como as organizações surgem ou 
se tornam estáveis. Mais especificamente, investiga como práticas e padrões adquirem condições de valores e são legitimados nas estruturas sociais. Em outras palavras, como são institucionalizadas as entidades. Essa abordagem teórica identificou, em nível macro, o isomorfismo institucional, isto é, a homogeneização de processos e estruturas das organizações que operam dentro de um mesmo campo, como forma de garantir a sobrevivência, ou permanência, por intermédio de legitimação (DIMAGGIO; POWELL, 1992). Soma-se a esse processo, em nível micro, a construção de normas compartilhadas pelos atores individuais por meio de diferentes variáveis que interagem entre si, se constituindo na base da legitimação das ações (ESMAN, 1966; ESMAN; BLAISE, 1972). Os indivíduos, responsáveis pela execução de tarefas e procedimentos, personificam e validam os principais modelos funcionais de operação necessários para a adequação das entidades às demandas sociais, adicionando complexidade à situação, pois essas interações internas, juntamente com os enlaces externos que levam as ações isomórficas e as conduzem a um processo de homogeneização (DIMAGGIO; POWELL, 1983), nem sempre são ações publicamente antagônicas.

Dentro do conjunto das ações propostas para implementar o EaD no Brasil destaca-se o Projeto Piloto da UAB do Curso de Administração a distância, que iniciou em junho de 2006 e teve suas primeiras turmas concluídas em dezembro de 2010. Esse projeto configura-se em um consórcio formado por 25 IESP, federais e estaduais, apoiado pelo MEC, UAB e o Fórum das Estatais, por meio do Banco do Brasil (BB). Em relação ao quantitativo atendido inicialmente, o vice-presidente de Gestão de Pessoas e Responsabilidade Socioambiental do Banco contabilizou 14.000 alunos (sendo em torno de 7.000 oriundos da entidade) e o envolvimento de 18 Estados da Federação (UAB, n.d.). Com base no escopo delineado, traçou-se como objetivo desse estudo descrever como está ocorrendo o processo de institucionalização do Curso ofertado pela Universidade Federal do Rio Grande do Norte (UFRN). Assim, foram identificadas as principais ações isomórficas (anteriores e presentes), com vistas à sua legitimação e utilizada à abordagem conceitual proposta por Esman (1972) para o entendimento das variáveis que influem nesse processo. Para tanto, elaborou-se, com base em Magalhães (2004), uma survey fundamentada nas ações previstas pelo Plano Político-Pedagógico (PPP) do Curso.

O texto está estruturado da seguinte forma: primeiramente é realizada uma reflexão sobre o EaD no Brasil, mapeando apenas questões que cabem à compreensão do objetivo proposto. Posteriormente apresenta-se a TI e as 
formulações sobre os mecanismos isomórficos e o processo de institucionalização. Por fim, delineia-se a estrutura e os atores do Curso. As considerações finais trazem algumas reflexões sobre o processo em estudo com vistas a contribuir à sua legitimação.

\section{Conceituando Ensino a Distância no Brasil}

Embora haja muitas formas de se definir o EaD, em essência, a base da proposta está no requisito da acessibilidade, aliada ao fator de que muitos dos recursos e metodologias podem ser combinados em aplicações síncronas (dependentes do momento, pois ocorrem em tempo real) e assíncronas (independentes do tempo e que podem ser acessadas quantas vezes forem necessárias), aumentando o potencial da metodologia. Alguns autores como Cruz (2001) discutem se é mais adequado utilizar ensino ou educação ao se referirem à metodologia, contudo, não há ainda consenso a respeito da aplicação mais adequada dos termos, sendo usados indiscriminadamente. Perry e Rumble (1987 apud NUNES, 1994) e Belloni (2003) observam que há muitas denominações utilizadas e assinalam a complexidade da questão, a falta de unanimidade em torno do tema e das experiências, e a ausência de uma reflexão teórica que fundamente as práticas realizadas. Por ser esse debate pertinente aos objetivos delineados, convém observar que este trabalho se posiciona pelo Parecer n. 5.622/05, artigo 80, do MEC, que define o EaD como

[...] uma forma de ensino que possibilita a auto-aprendizagem com a mediação de recursos didáticos sistematicamente organizados, apresentados em diferentes suportes de informação, utilizados isoladamente ou combinados, $e$ veiculados pelos diversos meios de comunicação. (grifo nosso).

Registros indicam que os cursos em EaD foram implantados no Brasil no final do Século XIX, contudo é provável que as primeiras experiências no país não tenham sido devidamente anotadas quanto as suas datas. Talvez por isso, Belloni (2003) considere precária a documentação existente sobre o início formal de seu funcionamento, mas, ainda assim é possível traçar um perfil histórico recorrendo a algumas iniciativas, pois, de certa forma, um passo 
após o outro, elas sinalizam como o processo vem sendo construído no país. Particularmente falando do Rio Grande do Norte (RN), o estado desponta como pioneiro no atendimento dessa concepção. A primeira iniciativa deuse por volta da década de 1940, com a estruturação da experiência de maior destaque de difusão da educação pública criada até então: o Movimento de Educação de Base, (fundado pela Arquidiocese de Natal), que se distinguiu pela utilização do rádio no ensino em um sistema articulado com as classes populares (NUNES; TEIXEIRA, 1998). A incursão seguinte se deu no início da década de 1960, com o primeiro projeto desenvolvido pelo Governo $\mathrm{Fe}$ deral no país com a utilização da televisão, o Projeto Satélite Avançado de Comunicações Interdisciplinares (Projeto SACI), elaborado pelo Instituto de Pesquisas Espaciais da UFRN. A terceira ação ocorre em 1991 com o desenvolvimento do segundo maior projeto na metodologia com o emprego de multimeios (rádio, televisão e correspondência), oportunizada pela UFRN e pelo governo do RN: o Projeto 8 Cidades.

Os cursos de EaD difundidos no Brasil ocorrem segundo a concepção da Comissão da União Europeia, a de aprendizagem aberta e a distância. Suas ações possibilitam relações até então inéditas, que utilizam símbolos na construção compartilhada de significados codificados. E é nessa participação que a cultura do EaD interfere de forma significativa no ensino tradicional, representando um paradigma emergente. Esse processo representa uma influência não tão pacífica e que reflete um campo de conflitos políticos e sociais, incorrendo na imposição de dominações ou suscitando resistências, por significar a redefinição do papel do professor, do aluno e da IESP. Essa ponderação implica em repensar essas entidades e não limitar-se apenas às práticas educativas. A decorrência de tal constatação abre-se para mudanças culturais e institucionais, uma vez que transformam relações não apenas entre docentes e discentes, mas até entre saberes e regras institucionalizadas da ação de ensino- aprendizagem. Paralelamente a essa conjunção, com vistas à sua institucionalização, o Governo Federal vem construindo uma pauta que, em um processo evolutivo, começa a criar um contexto de ação próprio, propício à formação de um campo organizacional, rompendo limites com aspectos legais e burocráticos da normatização do ensino presencial.

Atualmente, em todo o país, desenvolvem-se experiências em EaD. No que tange à consolidação da modalidade no Brasil, a pretensão do MEC é que por meio da UAB tenha sido contemplado, ou o quanto antes, 100.000 alunos com ensino superior até o fim do ano de 2010. Conta para isso com 
infraestrutura e custos operacionais mais baixos do que no ensino presencial, pois através do estabelecimento de redes entre as instituições participantes, e já sedimentadas no setor, permite o atendimento de indivíduos geograficamente distantes dos grandes Polos. Entretanto, embora o que se possa perceber nessa breve narrativa seja um processo em expansão, o EaD ainda é um fenômeno recente, quando comparado ao ensino tradicional.

\section{Teoria Institucional}

Decorrente da abordagem contingencial, a Teoria Institucional traz reflexões sobre os elementos externos e internos, que motivam (ou pressionam) o processo de escolha dos atos organizacionais. Procurando explicar porque as organizações surgem, tornam-se estáveis ou transformam-se, assumindo determinados formatos, essa Teoria avalia fatores como ambiente, história e tecnologia, investigando como a definição de padrões assume a condição de valores e adquirem legitimidade nas estruturas sociais. Para alguns autores (BERGER; LUCKMANN, 1996; TOLBERT; ZUCKER, 1999), a institucionalização é o resultado de um processo, feito por fases, que infere na estrutura organizacional e incorrerá no desenvolvimento institucional. Já para outros (DIMAGGIO; POWELL, 1983; SCOTT, 1995) é um mecanismo de mudanças e transformações nas organizações, um agente que influirá de suas estruturas. E, para alguns outros, como Esman (1972), é um saldo da influência positiva e afirmativa de algumas variáveis.

Assim, institucionalizar uma ação implica em iniciar um processo de transformação e mudança capaz de alterar uma conjuntura anterior em outra distinta. Na análise de Esman (1972), esse processo é obtido pela relação de fatores exteriores e interiores à organização. Inicialmente tendo trabalhado como consultor para países em desenvolvimento na United States Agency for International Development - USAID, em 1966, o autor elaborou um modelo conceitual de construção institucional aplicado pela entidade com popularidade nos anos seguintes. Desde essa primeira publicação, o modelo ganhou contribuições, sendo que, no Brasil, o trabalho mais popularizado vem da parceria com Blaise. Os autores pontuam que o processo de institucionalização: 
Has been accomplished when it can be demonstrated that the organization embodies social and technological innovations, that at least certain relationships and action patterns incorporated in the organization are normative both within the organization and for other social units, and the support and complementarity in the environment have been atteined (ESMAN; BLAISE, 1966, p. 5).

Esman entende a institucionalização das organizações como um fenômeno advindo de uma mudança adaptativa requerida pelo ambiente. Propõe um modelo analítico, o institution-building process, compreendendo variáveis internas e externas para a conduta dos atores. Para Esman (1972), é necessário compreender qual o perfil de institucionalização que determinada entidade se encontra, pois não há como dizer, em termos absolutos, quando ela se tornou institucionalizada. Assim, propõe certos critérios (Figura 1) que, ao serem analisados, identificam qual a tendência de institucionalização dessa entidade.

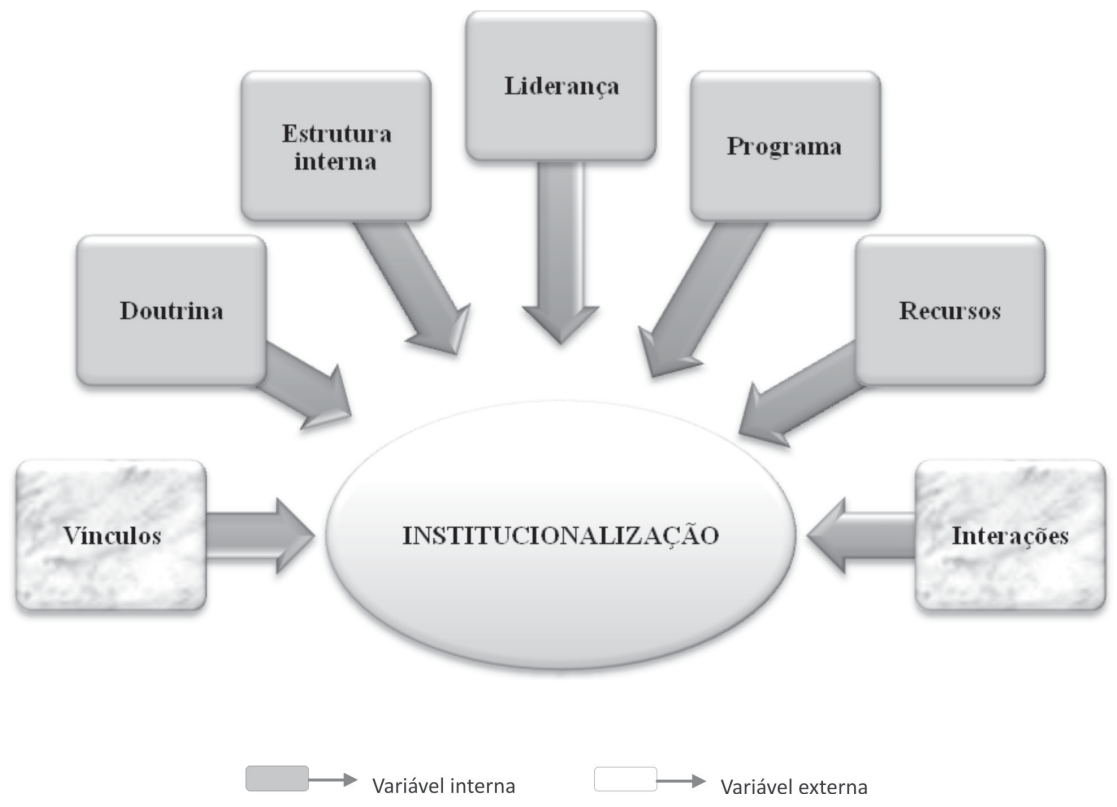

Figura 1: Processo de institucionalização

Fonte: Adaptada de Esman (1972)

A ideia fundamenta-se no desenvolvimento organizacional, em que o cerne da explicação é revelar como as variáveis, que não se comportam esta- 
ticamente, identificam o caráter institucional da organização, solidificando um sistema social, fruto de contingências dos diversos contextos ambientais. Essas variáveis permitem identificar os elementos que podem estar coibindo ou coadjuvando no processo.

A questão geral a propósito das variáveis internas, ou institucionais, é explicar o comportamento da instituição. Se o objetivo é compreender os elementos que abordam os arranjos informais em torno de estruturas e regras para que as metas sejam atingidas, as reações a serem estudadas estão relacionadas aos fatores como doutrina, estrutura interna, liderança, programa e recursos, que são, de acordo com o autor, o sustentáculo do funcionamento evolutivo interior. A variável doutrina é definida como "[...] the specification of values, objectives, and operational methods underlying social action". (ESMAN, 1972, p. 22), ou seja, uma exigência para o domínio das mediações inevitáveis dos atores institucionais. Se o objetivo é determinar os processos relacionados para operação e manutenção da instituição, relaciona-se à variável estrutura interna, pois ela estabelece a consistência, a adaptabilidade, o grau de complexidade, a relevância da eficiência organizacional, os níveis de decisão que dirigem à ação e o tipo de funcionamento exigido para a coexistência bem-sucedida do desenvolvimento.

A variável liderança é considerada o elemento crítico do processo. É explicada como o conjunto de pessoas engajadas em formular a doutrina e o programa e que se relacionam diretamente com o ambiente, exercendo influência contínua sobre as atividades. O entendimento da variável programa assimila o conjunto de atividades desenvolvidas para concretizar rotinas e padrões de comportamento das instituições, pois são "[...] those actions which are related to the performance of functions and services constituting the output of the institution". (ESMAN, 1972, p. 23). A variável recursos analisa os elementos necessários à concretização do programa, tais quais: entradas financeiras, físicas, tecnológicas, humanas e de informações, bem como fundos, equipamentos e instalações. Em suma, dados funcionais que trazem à instituição um sistema que oferece garantias as suas operações formais.

Esman (1972) explica as variáveis externas como as características que possibilitam a instituição interagir com o ambiente por meio de vínculos (elos institucionais) e transações. Veem-se as interdependências existentes, entre uma instituição e outros segmentos relevantes da sociedade, como relações exógenas às organizações, que proporcionam uma regulação social capaz de oferecer perspectivas de intervenção e orientar seus funcionamentos coletivos. Os vínculos são padrões de interdependência que existem entre organi- 
zação e ambiente. São sugeridos quatro: capacitadores, funcionais, normativos e difusos (na análise dessa pesquisa esses vínculos foram compactados e estabelecidos apenas como vínculos). As transações, são a mesma quantidade: "(1) gain support and overcoming resistence, (2) exchanging resources, (3) structuring the environment, and (4) transfering norms and values" (ESMAN, 1972, p. 22-23).

De acordo com Esman (1972), de um modo geral, tanto quanto em outras organizações essas variáveis podem ser observadas nas instituições de ensino. Contudo, ele ressalta, bem como Magalhães (2004), que as particularidades das atividades básicas desenvolvidas por universidades como pesquisa, ensino, armazenamento e disseminação, reforçam o envolvimento social dos atores internos com os membros da comunidade, fazendo com que trabalhem juntos e firmem ligações entre si, favorecendo os vínculos que levam à institucionalização. Em face dessas colocações, é preciso observar que como em nenhuma outra, as instituições educativas mantêm uma relação de conflitualidade permanente, endógena e exógena, com o ambiente, pois elas são, ao mesmo tempo, fornecedoras de mão de obra para o mercado, fontes de pesquisa e extensão, educadoras, adestradoras, palanques políticos e ambientes de trabalho dos atores que as fazem funcionarem, com seus próprios interesses e subjetividades. A análise de Magalhães (2004, p. 155) evidencia essa dualidade: "[... ] nada na vida de uma instituição escolar acontece, ou aconteceu, por acaso, tanto o que se perdeu ou transformou, como aquilo que permaneceu". Assim, ao apresentar em sua estrutura cursos a serem desenvolvidos por meio virtual, uma universidade passa a ter disposição e características paralelas, cuja infraestrutura oferece serviços e recursos on-line que se comportam, mais ou menos, como os mecanismos de uma entidade paralela. Destarte, o que fica evidenciado é que essa composição apenas permanecerá se o processo de institucionalização, defendido como "the planning, structuring, and guidance of new or reconstituted organizations" (ESMAN, 1972, p. 22), obter suporte e complementaridade do ambiente.

Ampliando o foco de análise, na abordagem do novo institucionalismo considera-se que o elemento fundamental para a adequação social seja o isomorfismo, que significa a conformação das organizações para um formato considerado legítimo em um determinado ambiente institucional. Sobre esse contexto, Scott (1995) ressalta que as semelhanças presentes nas características estruturais das organizações de um mesmo campo organizacional poderiam explicar o porquê de práticas e estruturas das universidades serem aná- 
logas. DiMaggio e Powell (1983) também abordam essa questão, delimitando-a como isomorfismo: um processo pelo qual as organizações passam a adotar as mesmas estruturas e práticas levando-as a uma homogeneização das unidades dentro de um contexto social. Ou, em suas palavras: "[...] um processo coercitivo que força uma unidade na população a se parecer com outras unidades que encontram o mesmo conjunto de condições ambientais" (DIMAGGIO; POWELL, 1992, p. 66). A ideia dirigente desses autores consiste que a principal motivação para que as organizações busquem se assemelhar estruturalmente às demais deriva mais de motivos contingenciais (que conduzem à legitimação) do que os econômicos (DIMAGGIO; POWELL, 1983; 1991), pois a reprodução de processos, práticas e rotinas que têm como finalidade a melhoria do desempenho e são considerados como sucesso em outras entidades é prática comum, tanto em organizações do setor privado quanto do público.

No que concerne à classificação dos tipos de isomorfismo, diferenciamse duas categorias: o competitivo, que diz respeito ao fenômeno, ligado à busca da eficiência, e segundo Hannan e Freeman (1977 apud SCOTT, 1995), é o resultado de pressões competitivas que forçam organizações a adotarem formas mais adequadas à sua sobrevivência; e o institucional, definido por DiMaggio e Powell (1983), que conduz efetivamente ao processo de institucionalização por ser relacionado à homogeneização de práticas, procedimentos e estruturas por parte de organizações. O fenômeno denominado isomorfismo institucional (SCOTT, 1995) é desenvolvido por meio de três mecanismos de mudança: coercitivo, mimético e normativo. As ações relacionadas ao isomorfismo coercitivo são práticas, estrutura, políticas e cerimônias, influenciadas por pressões externas, formais e informais, advindas de outras organizações com as quais a entidade mantém relação de dependência ou, ainda, de expectativas advindas da sociedade em que a mesma está inserida. $\mathrm{O}$ isomorfismo mimético refere-se a uma ação-resposta padrão de uma entidade as incertezas do ambiente, fazendo com que busque outras referências de estruturação e modelos de atuação que possam ser reproduzidos/copiados; portanto, regras e estruturas tendem a se assemelhar a outros modelos devido a dúvidas e insegurança que a acompanha no meio que atua. As relações de como determinados indivíduos formadores de percepções e opiniões e reconhecidos como possuidores de conhecimentos especializados desempenharão suas atividades dentro de uma organização é o que identificará ações de isomorfismo normativo. 
Assim ocorre com as atividades e ações executadas das e nas IESP no Brasil, levando a legitimarem sua existência e, mais especificamente, os principais modelos funcionais operacionais necessários para implementar valores. Pode-se dizer que ao objetivar a legitimação e a aceitação social, as IESP procuram aproximar suas ações e estruturas aos padrões tidos por corretos socialmente, em um processo inerentemente isomórfico (SCOTT, 1995). Essa conformidade, para as IESP, é buscada no sentido de garantir sua sobrevivência, via melhoria do relacionamento e reconhecimento da sociedade, tendo precedência sobre o desempenho organizacional propriamente dito (MEYER; ROWAN, 1991). Ademais,

[...] das atribuições e dos papéis que cabem e são esperados dos atores, [...], tal como são consignados nos regulamentos internos e nos normativos gerais, não informam, nem permite inferir sobre o grau de empenho e o norte da ação. (MAGALHÃES, 2004, p. 146).

Tornando-se um desafio, pois são "[...] as ações e os destinos de vida dos participantes [...]" que, especialmente, "[...] dão corpo e significado às realizações institucionais" (MAGALHÃES, 2004, p. 146).

\section{Metodologia}

Por levar em consideração aspectos históricos e suas inter-relações temporais frente a eventos que se sucedem, configura-se em uma pesquisa de natureza qualitativa, ainda que faça uso de métodos quantitativos de análise. Assim, o estudo foi concebido com finalidade exploratório-descritivo (MALHOTRA, 2005). Exploratório, na medida em que se voltou inicialmente à especulação das características de um fenômeno conhecido superficialmente, e descritivo, apoiando-se em Bruyne, Herman e Schoutheete (1977), que ressaltam que essa técnica deve estear-se em conceitos e ser guiado por um esquema teórico, o que ela o faz, com a utilização de um modelo de análise consolidado de Esman (1972). A abordagem metodológica identificada como adequada foi a survey, pois é indicada quando o objetivo é a descrição de eventos por meio da coleta de dados estruturada (MALHOTRA, 2005). 
Ao iniciar a revisão bibliográfica, constatou-se uma produção acadêmica e científica voltada aos processos de institucionalização adotando o estudo de caso, conforme salientam Scott (1995), Tolbert e Zucker (1999) e Machado-da-Silva e Gonçalves (1999). Como se pretendeu classificar a importância das variáveis de institucionalização para cada grupo de atores, averiguou-se que as respostas teriam mais acuidade com um método quantitativo. Para realização da pesquisa de campo, a população selecionada foram os atores do Curso de Administração a distância da UFRN, apresentados no Quadro 1.

\begin{tabular}{|c|c|}
\hline Sujeito & Quantidade \\
\hline Coordenador geral do Curso & 01 \\
\hline Coordenadores dos Polos de apoio estrutural & 03 \\
\hline Professores & 22 \\
\hline Monitores & 10 \\
\hline Tutores & 16 \\
\hline Secretária geral do Curso & 01 \\
\hline Secretárias dos Polos de apoio estrutural & 02 \\
\hline Alunos & 394 \\
\hline Total & $\mathbf{4 4 9}$ \\
\hline
\end{tabular}

Quadro 1: População da pesquisa

Fonte: Elaborado pelos autores

A característica mais importante da amostra foi definir os principais sujeitos que participam ativamente do processo no contexto acadêmico da UFRN. Para tanto, o estudo fundamentou-se em Magalhães (2004) que defende uma argumentação centrada em torno de alunos e professores. Assim, por terem como atribuições apenas tarefas não muito próximas da atividadefim do Curso, a função de secretária não foi elencada. Os sujeitos foram deliberados por universo amostral e por conveniência, excetuando-se os coordenadores (censitário). O método de amostragem foi estratificado em dois níveis de estágios (Figura 2). 


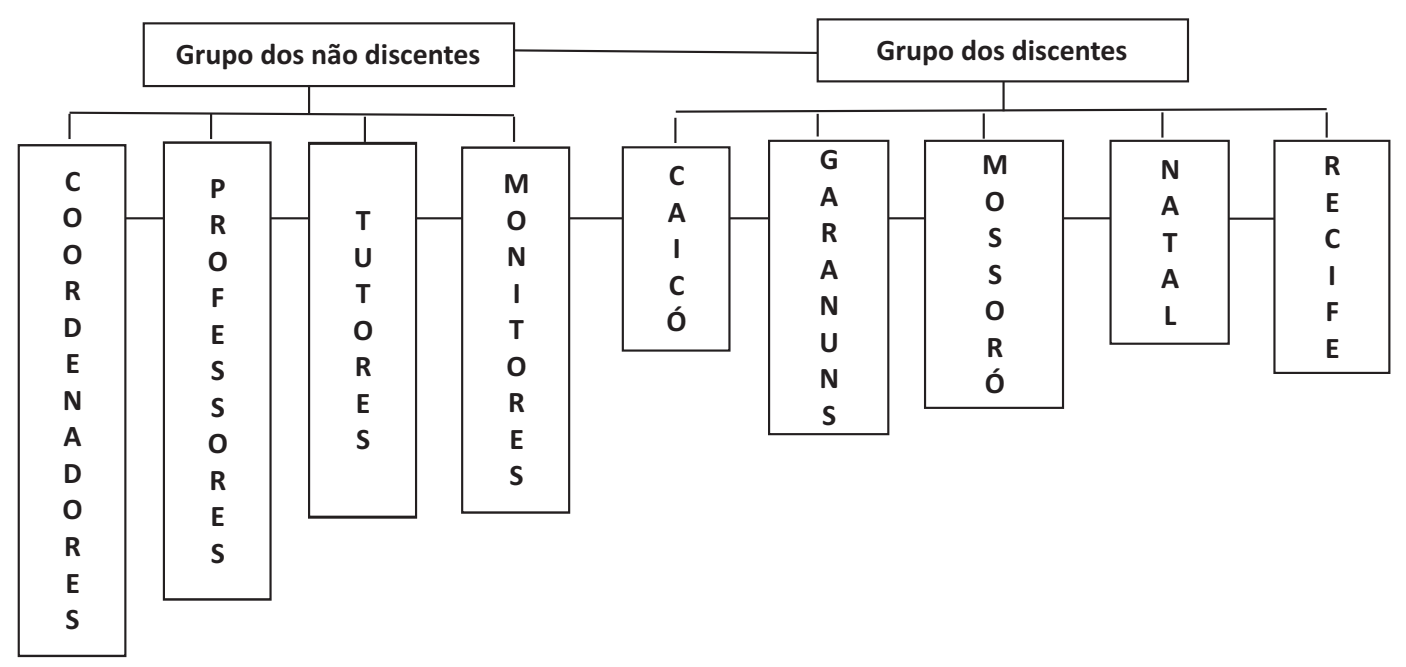

Figura2: Plano amostral do estudo

Fonte: Elaborada pelos autores

O critério de conveniência escolhido para realizar o estudo nas amostras deu-se de acordo com a disponibilidade dos entrevistados, portanto, fezse necessário conhecimento prévio sobre a distribuição da população da pesquisa, obtido com a coordenação do Curso. A amostra do grupo dos discentes foi estabelecida com nível de confiança de $95 \%$ e erro amostral de 6\%: Para os "não discentes", o nível de confiança foi $95 \%$ e o erro amostral de $8 \%$. Ambas as amostras foram constituídas por meio do cálculo proposto por Martins (1992):

$$
\mathrm{n}=\frac{\mathrm{Z}^{2} * \hat{\mathrm{p}} * \hat{\mathrm{q}} * \mathrm{~N}}{\mathrm{~d}^{2} *(\mathrm{~N}-1)+\mathrm{Z}^{2} * \hat{\mathrm{p}} * \hat{\mathrm{q}}}
$$

A demarcação da amostra do grupo "alunos" sopesou a variável área geográfica, sendo estabelecida mediante o critério de estarem lotados no mesmo Polo. Quanto ao grupo "não discentes", o critério de subdivisão foi determinado de acordo com o papel exercido. O Quadro 2 apresenta a relação final do universo amostral. 


\begin{tabular}{|c|c|}
\hline Sujeito & Quantidade \\
\hline Coordenador geral do Curso & 01 \\
\hline Coordenadores dos Polos de apoio estrutural & 03 \\
\hline Professores & 19 \\
\hline Tutores & 14 \\
\hline Monitores & 09 \\
\hline Alunos Natal & 109 \\
\hline Alunos Recife & 91 \\
\hline Alunos Mossoró & 32 \\
\hline Alunos Garanhuns & 22 \\
\hline Alunos Caicó & 10 \\
\hline TOTAL & $\mathbf{3 1 0}$ \\
\hline
\end{tabular}

Quadro 2: Universo amostral da pesquisa Fonte: Elaborado pelos autores

O presente estudo envolveu a coleta de dados de duas fontes, tendo sido iniciado pelas secundárias. Esse $1^{\circ}$ passo consistiu na compilação de informações já disponíveis, dando-se por meio de pesquisa bibliográfica $e$ documental, tais como o PPP e o site do Curso, ocorrendo no período de agosto de 2008 a março de 2009. Devido à constatação de conseguir informações não disponíveis nos instrumentos descritos foi implementada como base de dados primários uma survey, cujo questionário, elaborado e fundamentado no PPP do Curso, por ser, segundo Magalhães (2004) um instrumento de identidade da organização. Constituído por 39 perguntas fechadas, dentro da escala de Likert, de cinco pontos, não contemplou respostas evasivas e constou de duas partes: caracterização sociodemográfica $e$ evidenciação das variáveis isomórficas e identificação dos fatores que contribuem à institucionalização do Curso. Sua aplicação foi realizada de abril a julho de 2009, e sua tabulação e análise se deram por meio do aplicativo estatístico SPSS.

Assim, para os dados secundários foi utilizada a análise documental e empregada a análise descritiva para delimitar características isomórficas; para a análise das variáveis nominais e contínuas e para as questões sociodemográficas, utilizou-se estatística descritiva; e, para se obter a classificação das respostas por nível de amostra e poder verificar divergências, foi utilizada a Análise de Variância (Anova) de N fatores - essa opção deveu-se 
ao intuito de determinar quais as variáveis do modelo de análise de Esman (1972) que influenciam na institucionalização do Curso. Por fim, devido à Anova não identificar onde se encontram especificamente as diferenças, foi utilizado como teste de acompanhamento o de Tuckey, por ser, segundo Hair (2005), apropriado para pesquisas em Administração.

\section{Apresentação do Curso e Discussão dos Resultados}

O Curso de graduação em Administração a distância iniciou como um projeto piloto, fruto de uma proposta formulada pelo MEC com o apoio do $\mathrm{BB}$, cujo papel não se restringiu a ser de mero expectador e fornecedor de demandas (MENELAU et al., 2008). Analisando declarações, foi possível constatar que além de ter desenvolvido o cerne do projeto e de colocá-lo à disposição do MEC, o Banco também negociou com as IES federais e estaduais. A ideia inicial, como comenta Luiz Souza, do BB, era a de ter um estado por região. Contudo, ele expôs as dificuldades: "Atrasamos esse piloto para podermos colocá-lo em todos os estados, mas infelizmente algumas universidades não deram resposta. Entretanto, o Banco vai continuar insistindo nas negociações com essas instituições" (<http://www.universia.com.br/> Acesso em: 25 ago. 2007). Corroborando com essa afirmação, para o curso piloto foram inscritas apenas 17 Universidades Federais, representando apenas $38,64 \%$ do total, que se somaram a mais sete estaduais, correspondendo a $22,58 \%$ de instituições por essa dependência administrativa, na data de sua criação (http://www.inep.gov.br/> . Acesso em: 25 ago. 2007). Pelo projeto piloto inicial cada instituição atenderia um número mínimo de 500 alunos, oriundos do $\mathrm{BB}$, de outros bancos públicos e alguns parceiros de entidades públicas, ainda no primeiro semestre de 2006.

Portanto, a política para formulação do Curso partiu de um problema concreto de interesse do $\mathrm{BB}$ que almejava qualificar cerca de 35.000 funcionários que não possuíam nível superior, e do Governo, que pretendia avaliar um curso de graduação a distância com abrangência nacional. Assim, financiado parcialmente pelo $\mathrm{BB}$, a ideia do projeto é a de que o Curso atendesse em torno de 10.000 alunos e que fosse o mesmo para todo o país, tornandose um desafio para as instituições participantes, haja vista as diferenças curriculares entre as suas propostas de ensino (MENELAU et al., 2008). Na UFRN, o PPP do Curso sinaliza que sua criação é oriunda do atendimento de uma política do Governo para ampliação do acesso ao ensino superior 
e a formação de servidores públicos. Consta também que seu invento se deve à necessidade de atendimento a estudantes residentes em regiões sem IESP.

De acordo com Menelau et al. (2008), na UFRN a oferta do Curso se dá sob a batuta e supervisão da Secretaria de Educação a Distância da UFRN (SEDIS), que é responsável ainda pelo desenvolvimento de mais quatro cursos de graduação em Licenciaturas. Os cursos fornecidos pela SEDIS são ministrados por multimeios, destacando-se o ambiente virtual de aprendizagem (moodle). O Curso da UFRN começou a ser oferecido apenas no $2^{\circ}$ semestre do ano de 2006, mediante parceria entre o MEC, a entidade e as Universidades de Pernambuco e a Federal de Santa Catarina. Inicialmente, estreou suas atividades com 596 alunos. Após o primeiro semestre letivo o número caiu aproximadamente 15\%, tendo, no início do ano de 2007, 507 alunos regularmente matriculados. Atualmente, tem inscrito aproximadamente $66 \%$ do montante inicial, ou seja, 392 alunos, sendo, em sua maioria, ingressos do BB. A estrutura física conta com cinco Polos de apoio ao atendimento presencial, acesso à plataforma e suporte às aulas virtuais distribuídos nos Municípios de Caicó, Mossoró e Natal - no RN; e em Garanhuns e Recife - em Pernambuco. A coordenação do Curso dispõe de apoio técnico e pedagógico, disponibilizada pela SEDIS. A todas essas operações vêm acrescentar o esquema formal para execução das atividades, previsto com hierarquia de competências (Quadro 3).

\begin{tabular}{|l|l|}
\hline \multicolumn{1}{|c|}{ Função } & \multicolumn{1}{c|}{ Atividade } \\
\hline $\begin{array}{l}\text { Coordenador geral } \\
\text { do Curso }\end{array}$ & Acompanha e avalia o processo de execução pedagógico e administrativo. \\
\hline $\begin{array}{l}\text { Coordenadores dos } \\
\text { Polos de apoio }\end{array}$ & $\begin{array}{l}\text { Respondem pelo acompanhamento de estudantes e tutores que } \\
\text { compõem os Polos que são responsáveis. }\end{array}$ \\
\hline Secretária acadêmica & $\begin{array}{l}\text { Exerce atividades como manutenção da plataforma, gestão de docu- } \\
\text { mentos e arquivos. }\end{array}$ \\
\hline Professores & $\begin{array}{l}\text { Responsáveis pelas disciplinas dos módulos, podendo ministrar em } \\
\text { algum outro novamente. Disponibilizam-se para esclarecimento de } \\
\text { dúvidas de estudantes e/ou tutores. }\end{array}$ \\
\hline Monitores & $\begin{array}{l}\text { São distribuídos dois para cada disciplina, atuando como assistentes } \\
\text { dos professores. Não têm permissão para modificar conteúdos e linhas } \\
\text { pedagógicas. }\end{array}$ \\
\hline Tutores & $\begin{array}{l}\text { Estão distribuídos pelos Polos, atuando como elo entre estudantes e } \\
\text { instituição. São facilitadores da aprendizagem, pois elucidam dúvidas } \\
\text { de alunos em relação ao conteúdo. }\end{array}$ \\
\hline
\end{tabular}

Quadro 3: Função e atividades dos atores do Curso

Fonte: Elaborado pelos autores 
Na investigação inicial, foi possível constatar algumas incongruências no dimensionamento da equipe, conforme previsão do PPP: 1) o Polo Natal não tem coordenador próprio, bem como o de Garanhuns e o coordenador geral (lotado na UFRN) acumula funções, pois também exerce o ofício de coordenador do Polo Natal; 2) os coordenadores dos Polos não são todos oriundos da UFRN, sendo dois advindos de uma das instituições parceiras (UPE); 3) os Polos Caicó, Garanhuns e Natal não têm secretárias acadêmicas próprias e a secretária geral (em Natal) ajunta a função de secretária acadêmica deste Polo; 4) quanto à função professor, o Curso não conta ainda com quadro fixo próprio, sendo os professores dos cursos presenciais da UFRN. Essas constatações, sem dúvida alteram a dinâmica esperada das ligações de trabalho, pois se tratam do equilíbrio das relações entre os atores. A elas, somam-se ainda dois efeitos perversos à legitimação da função de identidade do Curso. A primeira refere-se à construção e incorporação de valores $e$ significados comuns em pessoas que apesar de formarem, oficialmente, parte do mesmo grupo, não participam, de forma síncrona e coletivamente, das experiências, por fazerem parte de estruturas físicas, locais, departamentos e instituições com diferentes normas, regras e procedimentos. A segunda está em torno da participação de professores e coordenadores. O sistema UAB estabelece bolsas, depositadas como um montante extra em seus salários. Essa ação, ao contrário de beneficiar a institucionalização do Curso vai de encontro à lógica de ação legítima ao estabelecer um valor monetário e não admitir o reconhecimento do exercício da função como hora aula docente, prevista nas relações contratuais desses profissionais.

No que concerne ao perfil do grupo dos discentes, a maior parte, $75,1 \%$, está lotada nas capitais e não nas demais cidades, não incorporando a definição do UAB, prevista no artigo $1^{\circ}$ do Decreto 5.800/96, do qual o Curso faz parte, que diz que esse deve ser um Sistema voltado "[...] para o desenvolvimento da modalidade de educação a distância com a finalidade de expandir e interiorizar a oferta de cursos e programas de educação superior no País" (grifo nosso). O perfil geral de distribuição dos alunos indica que a população masculina é maioria na composição total deste grupo, 73,4\%, o mesmo acontecendo nos Polos individualmente. Em relação à faixa etária, a maioria tem idade entre 41 e 50 anos, representando um percentual de 41,8\%, o que indica a disposição dos cursos praticados a distância que, apesar de esforços, continuam atendendo, em sua maioria, a pessoas que necessitam de ensino em condições diferenciadas. Ressalve-se, que o segundo maior 
quantitativo desse subgrupo é composto por pessoas em idade entre 21 e 30 anos, implicando em $21,5 \%$ da amostra.

Quanto à escolaridade anterior ao Curso no grupo dos discentes, apenas $11,1 \%$ tem graduação completa, o que condiz com os objetivos formulados pelo consórcio de proporcionar capacitação aos funcionários do BB e demais organizações. Registre-se aqui que os dados içados por esta pesquisa, no que se refere à escolaridade, quando comparados entre si não refletem desigualdade no nível de ensino dos alunos dos cinco Polos e que, por outro lado, duas peculiaridades se apresentaram: todos os alunos que informaram ter pós-graduação completa estão lotados em Caicó e, o segundo maior percentual de alunos com graduação anterior ao Curso (18,2\%) situase em Garanhuns, e não em Recife, uma das duas capitais, ainda que a maioria do alunado com ensino superior completo $(18,4 \%)$ esteja em Natal. Apesar de o Curso na UFRN ser formado por uma única turma piloto, $77,4 \%$ dos alunos relatou não ter frequentado desde o início, tendo apenas 22,6\% declarado estar desde o princípio do Curso e 4,2\% ter afirmado que estuda há apenas 1 e 2 anos. O estudo refletiu que 100\% dos alunos ingressaram por meio de um processo seletivo, o que denota uma contribuição à institucionalização e um indicador favorável à variável liderança (ESMAN, 1972).

Analisando as informações sobre a renda mensal individual dos alunos, a fatia de renda acima de $\mathrm{R} \$ 2.500,00$ foi a que recebeu maior percentual de pessoas, seguido por $15,3 \%$ das que trabalharam com renda acima de $\mathrm{R} \$$ $1.500,00$ até $\mathrm{R} \$ 2.000,00$. Portanto, no conjunto dos cinco Polos pesquisados, constata-se que, independente da qualificação atual, mais da metade dos alunos estão situados entre as classes A e B, segundo classificação do Instituto Brasileiro de Geografia e Estatística - IBGE (2009). Ao traçar um paralelo entre qualificação e renda, foi apurado que $73,9 \%$ dos alunos têm como escolaridade nível superior incompleto e renda acima de $\mathrm{R} \$ 2.500,00$.

No grupo dos "não discentes", a distribuição geral por cargos corresponde ao que foi escalonado no PPP e há predominância do sexo feminino $(58,7 \%)$. Ao nível da distribuição por idade, quando se tem uma visão geral do conjunto, as faixas etárias não apresentam nenhuma incoerência, bem como a escolaridade registrada. Quanto à dinâmica de contratação, ela está atrelada à articulação dos atores e à interação entre seus pares. As coordenações, geral ou de Polo, juntamente com professores e monitores repousam nessa premissa. Já a de tutor se apoia nos princípios de definição de uma estrutura formal organizacional, seja ela uma instituição 
acadêmica ou não: a ocupação do cargo por seleção e por mérito. Se, por um lado, a institucionalização contribui para a integração entre os subgrupos, por outro, o que aqui se apresenta é a confrontação das regras institucionalizadas pela IESP e pelo ambiente externo do qual o Curso faz parte que, de acordo com Esman (1972), poderá se traduzir na construção negativa da doutrina, fundamental para a consolidação dos valores e da coesão entre os indivíduos e também refletindo negativamente na variável liderança e nas interações do Curso com o ambiente externo.

Uma função merecedora de que sejam feitas algumas considerações é a de monitores. A dinâmica do Curso prevê dois indivíduos por disciplina, o que resultaria em um percentual maior ao apresentado por esta pesquisa. Contudo, um importante contexto relacional foi criado entre eles e os professores, diminuindo o turnover e ampliando sua participação no Curso. Essa ação demonstra que foram criados parcerias e vínculos afetivos, que contribuem para a sedimentação dos valores, hábitos e rotinas necessárias à institucionalização. Analisando o tempo de vínculo empregatício apresentado pelo grupo dos não discentes e comparando-o com o perfil profissional, pode-se observar que os dados condizem com o previsto pelo PPP, ou seja, os monitores situam-se em uma faixa de tempo que vai de um ano até o tempo total do Curso, o vínculo dos tutores e dos coordenadores está concentrado no tempo de duração do Curso, e os professores que participam (ou participaram) apresentam um tempo consoante à sua contratação. $\mathrm{O}$ pecúlio declarado pelos professores e coordenadores assinala que $100 \%$ situam-se na classe A -, segundo o IBGE (2009). Essa informação permite inferir que suas participações nesse Curso podem não ser apenas decorrentes do aumento salarial. Para os demais, tal qual no grupo dos alunos, as informações sobre escolaridade e renda não associa a alta remuneração ao tempo de permanência do indivíduo na escola: quem declarou ter ensino superior completo, $100 \%$, recebe menos de $\mathrm{R} \$ 1.000,00$. Portanto, dos resultados até aqui apresentados verificam-se as variações complexas do ambiente interno.

Em dois pontos específicos na análise do perfil dos alunos, os resultados devem ser ressaltados como não favoráveis à institucionalização do Curso. O primeiro se refere à localização: o perfil identificado contraria a recomendação do artigo 80 da Lei 9.394/96, que prevê veiculação de "programas de ensino a distância". Programas, no que se alude ao jargão da Administração Pública e ao Poder Público, são iniciativas para atender demandas específicas, o que, no caso do $\mathrm{EaD}$, corresponde a pessoas que estão em 
regiões com deficiência de ensino, o que não foi constado por este estudo, influenciando negativamente a variável vínculos. O segundo ponto corresponde ao tempo de entrada dos alunos. Para que haja apropriação e incorporação dos valores e símbolos, importantes elementos presentes na composição da variável doutrina, faz-se necessário que os atores se apropriem desses componentes. O que somente se dará por meio da participação de rotinas, hábitos e padrões do cotidiano compartilhado, cuja articulação de um curso a distância (devido ao próprio Sistema) não favorece a formação de uma identidade, configurando esse ponto como um fator desfavorável, de acordo as premissas adotadas por este estudo para análise da institucionalização.

É possível constatar que no Curso foram adotadas práticas, procedimentos e estruturas análogas a outras entidades que abraçaram os cursos de EaD da UAB. Dessa forma, destacam-se nessa pesquisa as três tipologias de ações isomórficas, propostas por Powell e Dimaggio (1983; 1992). Percebese que uma das primeiras ações isomórficas presentes no Curso é a sua criação em si e, concomitantemente, sua instalação na UFRN. A parceria entre o Banco do Brasil e o MEC seguiu, primeiramente, a recomendação política do Banco Mundial para que a educação superior a distância dos países do sul acontecesse mediante a participação de outros setores, pois deveriam "[...] colaborar com o setor público para introduzir a tecnologia nas escolas e universidades" (BANCO MUNDIAL, 1999, p. 87). Verifica-se, quase 10 anos depois, a consolidação dessa recomendação, pois a proposta de validação do Curso, em nível nacional, ocorreu em 2009 e as inscrições foram abertas para a população em geral. Especificamente relacionado ao objeto de estudo dessa pesquisa, a fundação do Curso - caso claro de isomorfismo normativo - se deveu ao atendimento de uma demanda política do Governo Federal para ampliação do acesso ao ensino superior na região, como assinalado no PPP. A própria adesão da UFRN ao Curso toma o formato de uma ação induzida, de modo a proporcionar a entidade um formato considerado legítimo. Pioneira no uso de tecnologias aplicadas à educação, a UFRN é uma das poucas IESP no Brasil que possui experiência com a modalidade anterior ao UAB, contudo, não estava entre as primeiras a se comprometer a veiculá-lo. Sua entrada apenas se deu no segundo semestre do ano de 2006, caracterizando-se uma ação nos moldes do isomorfismo mimético.

Duas questões foram inseridas no questionário, direcionadas a descobrir similaridades entre a estrutura do Curso da UFRN e os demais da UAB e 
outra relacionada à sua similitude e os demais presentes no ambiente. Quando a pergunta se direciona à homogeneização das práticas dentro do projeto, $40 \%$ dos respondentes não sabem afirmar se o que acontece no Curso tem relação com o que acontece nas outras IESP. Desse total, 47,1\% corresponde aos alunos. Por outro lado, no grupo "não discentes", 58,7\% fazem o diagnóstico que essa ação tem acontecido. Bem, se for considerado apenas o resultado apurado no grupo dos não discentes, o que se confirma é o estabelecimento de um contexto favorável, uma rede integrada entre as IESP participantes do projeto do Curso, essencial à legitimação no ambiente. Essa rede de informações, práticas e cooperação conduz ao êxito do projeto e se constitui em uma ação de isomorfismo normativo. Essa similaridade que o UAB está buscando estabelecer entre as IESP, tal qual ocorreu na Inglaterra com a Open Universty, poderá proporcionar um ambiente favorável à institucionalização do Curso e, consequentemente, da modalidade.

Quando a pergunta direcionou-se a apurar, se há similaridade entre o Curso e os demais praticados no ambiente por outras instituições escolares, $85,6 \%$ da população concordam que está em conformidade com os demais dos quais têm conhecimento. É oportuno salientar que esse diagnóstico implica que está havendo a criação de uma cultura de EaD no Brasil, pois é possível a esses participantes, em algumas atividades, medir e comparar. Essa dinâmica aceita pelos indivíduos pesquisados reflete o alcance de uma significação comum e, é bem verdade, resultado de um mecanismo normativo, advindo, a priori, de uma regulação do Estado e do próprio ambiente. Contudo, essa descoberta pode ser vista positivamente para a construção da institucionalização deste Curso, e dos demais oferecidos no Brasil, pois é a confirmação de um processo de mudança em andamento: não apenas o sistema presencial é reconhecido, mas também o sistema de EaD.

$\mathrm{Na}$ análise das variáveis internas, a variável doutrina foi a que apresentou o melhor resultado. A média geral obtida dos entrevistados significa concordância plena com o perfil adotado pela gestão em sua condução, ou seja, os respondentes se identificam com os valores que estão sendo implantados pela linha de ação do Curso, segundo a proposta de Esman (1972). Na variável estrutura interna, a média auferida indica que a maioria concorda com a concepção estrutural de suporte do Curso, excetuando o método escolhido de avaliação dos alunos, presencialmente - o que não é uma exclusividade deste Curso e, sim, uma imposição universal da política adotada pelo MEC aos programas de EaD no Brasil. Portanto, pode-se considerar que estrutura 
interna também conta com a aprovação. Para o exame da variável liderança, foram solicitadas apenas as opiniões dos não discentes para julgar elementos que permitem a viabilidade e continuidade do Curso, por meio das ações adotadas pela gestão, como também a competência dos atores. $\mathrm{O}$ obtido sugere que os participantes demonstraram que muitas das informações auferidas eram desconhecidas. Aqui cabe ressaltar que essa variável é considerada por Esman (1972) como condicionante ao sucesso da institucionalização. Para averiguação da variável programa foram elaboradas questões sobre o modus operandi, investigando aspectos inerentes às atividades desenvolvidas na prática do método de ensino-aprendizagem. As respostas obtidas com os discentes alternam entre a demonstração de total desconhecimento de instrumentos de avaliação do grupo dos não discentes e a aprovação incondicional da desenvoltura da atuação deles. Isso implica na probabilidade de que entre as ações previstas e as executadas exista ou um gap, ou uma falha comunicacional. No estudo da variável recursos, os atores avaliaram os instrumentos utilizados pela gestão para viabilizar o Curso. Os resultados expõem que a elevação de sua média geral se deve, única e especificamente, à utilização da internet. Na contramão, o fator que definitivamente conformou a essa variável um resultado negativo foi a aversão, de ambos os grupos, pela utilização de material impresso. Esse resultado reforça a importância do uso das TICs na popularização e legitimação da modalidade.

Por fim, os atores analisaram a variável externa vínculos-intercâmbios, que expôs que muitos dos fatores perguntados sobre interações, trocas e permutas com o ambiente eram desconhecidos aos dois grupos. Esse resultado pode, a médio e longo prazo, conduzir essa iniciativa a um baixo grau de apropriação, que poderá findar em mais uma ação fragmentada da modalidade, de acordo com as premissas adotadas pelo estudo. Há ainda, em relação à análise das variáveis, uma ressalva: a ausência de atividades de pesquisa e extensão para os alunos. Previstas no PPP, tanto os não discentes quanto os alunos indicaram não saber sobre tais atividades. Com isso, pensar no Sistema UAB como uma universidade virtual coincidirá no mesmo plano de reflexão de permanecer chamando a modalidade de educação. 


\section{Considerações Finais}

O trabalho buscou descrever como as ações articulativas dos atores auxiliam ou dificultam a criação de valores, símbolos e padrões compartilhados que irão conduzir a legitimação de um novo modelo no ambiente, de acordo com a TI. Fixou-se como objetivo geral fazer uma descrição de como está ocorrendo o processo de institucionalização do Curso de Administração a distância da UFRN. Diante disso, a explicação fundamentou-se em autores da TI. Com base nesse escopo, Machado-da-Silva e Gonçalves (1999) recomendam que os estudos institucionais façam uso do arcabouço teórico do velho e do novo institucionalismo para proceder à análise, e assim o foi, pois essa análise considerou o papel do ambiente nas ações do Curso, identificando os tipos de isomorfismos presentes, mediante tipologia de estudo definida por Dimaggio e Powell (1983). Seguindo ainda sugestões (SCOTT, 1995; TOLBERT; ZUCKER, 1999) adicionou-se nessa análise, tradicionalmente realizada por métodos qualitativos, técnicas estatísticas quantitativas para captar as variações entre as ações dos grupos.

Ficou evidente que a ampliação do contexto dos cursos ministrados na modalidade a distância está confessadamente posta no sistema de educação superior do Brasil, pois, o Governo Federal além de amparar a modalidade com legislação própria, cada vez mais implanta iniciativas nesse sentido. Essa atitude caracteriza-se como uma ação de isomorfismo normativo (DIMAGGIO; POWELL, 1992), não apenas no ambiente da UFRN como também às outras IESP, envolvidas ou não no Curso de Administração a distância. No horizonte das IESP essa é uma realidade que avança destemidamente, com o intuito de aumentar a quantidade de vagas e de formandos e, assim, cumprir as determinações instituídas por agências internacionais. Nesse processo encontram-se como metas a legitimação da modalidade e do Curso de Administração oferecido pelo UAB.

Com o intuito de ressaltar a resposta ao objetivo delineado, considerou-se por bem fazer distinção entre educação e ensino, apesar de boa parte da literatura sobre $\mathrm{EaD}$ não considerar ser necessário fazer a dessemelhança. Segundo Magalhães (2004), a ação educativa compreende um conceito amplo, de desenvolvimento do indivíduo por construções coletivas e individuais, articulada com os direitos sociais. Já por ensino deve-se entender como a "[...] escolarização formal numa instituição específica [...]" (FÉTIZON; MINTO, 2007, p. 94), sistematizada na seleção de conteúdos e métodos. 
Portanto, o primeiro ponto no intuito de refletir em como está se dando a institucionalização é determinar que, segundo o apurado por esta pesquisa e que também é estabelecido pelo Parecer n. 5.622/05, no artigo 80, o Curso vem se desenvolvendo de acordo com os preceitos de ensino a distância e não de educação a distância, como se convencionou chamar o Sistema como um todo.

Essa definição é importante no sentido de enfrentar que o modelo que está sendo adotado pelo Governo não deve ganhar o escopo de um mérito maior do que o colocado. Essa acepção também traz outra implicação, pertinente à institucionalização do Curso e da modalidade. Um contexto educacional que não se desenvolve articulado por construções coletivas, ainda que possua regras e estruturas que tendem a se assemelhar, não consegue institucionalizar práticas e/ou organizações (ESMAN, 1972), mesmo que advenha como uma modificação adaptativa requerida pelo ambiente, pois são os participantes (principalmente, os alunos) que legitimam a conjuntura (MAGALHÃES, 2004). Nesse sentido, pode-se considerar que as IESP que atuam na modalidade de EaD ainda não constituem um campo organizacional, conforme as premissas de Powell (2007), o que significaria o desenvolvimento de uma consciência comum entre os participantes em, pelo menos, todos os principais pontos, representando assim a institucionalização da modalidade.

O segundo parâmetro a ser discutido é a criação e o estabelecimento do Curso no contexto da UFRN. As evidências mostram que essa iniciativa foi advinda de pressões isomórficas, influenciada por constrangimentos externos, formais e informais, que resultaram em sua implantação. A disposição social e estrutural organizada em torno do $\mathrm{EaD}$, especificamente neste Curso, não é resultado de uma evolução espontânea da instituição: as regulações dominantes conduziram a entidade a essa mudança. A pesquisa mostrou que apesar da UFRN ter sido pioneira na aplicação de metodologias diferenciadas, a adoção do Curso se deu por meio de pressões coercitivas e normativas do ambiente.

Entretanto, o conjunto de fatores isomórficos, tal qual sugerido por DiMaggio e Powell (1992) e apontado pelo estudo, fruto da regulação do Estado, do próprio ambiente institucional da entidade, das exigências da sociedade e dos organismos internacionais, alcançou uma significação comum. $\mathrm{E}$, diante disso, no momento, esses elementos podem ser considerados a favor da construção de sua institucionalização, ainda que ajustes devam ser 
realizados no sentido de minimizar os embates cotidianos. Com relação a esse aspecto, destaca-se a adoção, pelo Estado, de um novo modelo de ensino, sua legitimação e posterior ação no intuito de institucionalizá-lo, com a criação de um sistema protegido (UAB) e legalizado e a utilização de regras e procedimentos padronizados que, no estudo em questão, centrou-se na criação e implantação do Projeto Piloto do Curso e da utilização pelas IESP participantes de um PPP análogo em todas elas.

A ideia-chave de análise dos fatores que estão influenciando para mais, ou para menos, o processo de institucionalização do Curso foi estruturada no PPP. O instrumental utilizado para o alcance desse objetivo específico foi o modelo de análise proposto por Esman (1972), adaptado, que em sua conceituação original consiste em sete variáveis, internas e externas. Aqui, a investigação se estruturou em seis (condensando as duas externas), utilizando-se a Anova para especular se uma ou outra variável teria maior ou menor influência no referido Curso. Contudo, antes de discorrer sobre essa análise em si, cabe um breve comentário sobre a investigação da população. Os atores do Curso foram divididos em dois grupos, os "não discentes" e os "discentes", e depois, subdividos por função (não discentes) e por Polos (discentes). O objetivo dessa disposição foi perceber se as variáveis de institucionalização de Esman (1972) teriam a mesma influição nos dois conjuntos de atores.

Na investigação das variáveis, verificou-se que os dois grupos de atores pesquisados têm diferentes pontos de vista para os elementos interpelados. Contudo, no grupo "não discentes", o que se constatou é que, como em nenhuma outra combinação, as respostas dos coordenadores se assemelhavam assaz às dos tutores. Isso leva a supor que esses dois subgrupos, com papéis mais perenes dentro do Curso, adotaram características protetoras para os relacionamentos, padrões e normas implantados. O mesmo fenômeno, mas não tão enfático, pôde ser observado nas respostas dos alunos lotados nos Polos das duas capitais. Da análise do modelo proposto por Esman (1972), o que se pode concluir é que apenas as variáveis internas doutrina e estrutura interna podem estar influenciando positivamente o processo de institucionalização do Curso. Por outro lado, o resultado encontrado às demais permite concluir que a institucionalização do $\mathrm{EaD}$, por meio do Curso de Administração, ao manter o rumo praticado até o presente momento, pode ter dificuldade para alcançar os níveis de legitimação necessários para que seja vista como uma proposição sedimentada pelo ambiente, segundo as premissas de institucionalização de Esman (1972) adotadas pelo estudo. 
Entretanto, ao considerar que a análise se refere a um Projeto Piloto, há de se cuidar para que os entraves apresentados, e contrários à institucionalização do Curso de Administração a distância, sejam reconstituídos e que possam ser progressivamente substituídos por práticas e procedimentos respaldados por atores e ambiente. Por fim, esse estudo acredita que o conjunto das ações que estão sendo implantadas e executadas favorece e potencializa o processo, e a ausência de uma ou de outra implica na reversão dos progressos obtidos até o momento no êxito de sua institucionalização. Ademais, como bem colocam os autores da TI (DIMAGGIO; POWELL, 1992; SCOTT, 1995; TOLBERT; ZUCKER, 1999), toda mudança implica em construção e edificação de novos símbolos, valores e na implantação de uma nova rotina. A evidenciação dessas verdades é a condição sine qua non para o êxito de um processo de institucionalização.

\section{The Institutionalization of Distance Education in Brazil: the case of the Administration Course at University Federal of Rio Grande do Norte (UFRN)}

\section{Abstract}

The Distance Learning (DL) has in Pilot Course of Management an important initiative for dissemination in the country. This is configured in a consortium of 25 Higher Education Institutions (HEI), supported by the MEC, by the Open University of Brazil (UAB) and the Bank of Brazil (BB). This paper seeks to understand the process of institutionalization in this UFRN, identifying key actions isomorphic with a view to its legitimacy. We adopted a qualitative research, although techniques have been added as survey statistics, Anova $\mathrm{N}$ factors and the Tukey test. The survey showed that HEIs working with distance education does not constitute an organizational field and the creation and the establishment of the Course in the UFRN isomorphic pressures were coming from outside, but only the internal variables positively influence the institutionalization of the course.

Key words: Institutionalization. Distance Learning. Administration Course. 


\section{Referências}

BANCO MUNDIAL. Documento estratégico do Banco Mundial: a educação na América Latina e Caribe. 1999. Disponível em: <http:// www.bancomundial.org.br. >. Acesso em: 9 abr. 2007.

BELLONI, M. L. Educação a distância. 3. ed. Campinas: Editores Associados, 2003.

BERGER, P. L.; LUCKMANN, T. A construção social da realidade. Petrópolis: Vozes, 1996.

BRASIL. Lei n. 9.394, de 20 de dezembro de 1996. Dispõe sobre as diretrizes e bases da educação nacional. Diário Oficial da União. Brasília, DF: Ministério da Educação e Desporto. 1996.

. Decreto n. 5.622, de 19 de dezembro de 2005. Dispõe sobre o artigo 80 da Lei n. 9.394/96. Diário Oficial da União. Brasília, DF: Ministério da Educação e Desporto. 2005.

. Decreto n. 5.800, de 08 de junho de 2006. Dispõe sobre o Sistema Universidade Aberta do Brasil. Disponível em: <http:// www.planalto.gov.br/ccivil_03/_Ato2004-2006/2006/Decreto/D5800.htm > . Acesso em: 9 abr. 2008.

BRUYNE, P.; HERMAN, J.; SCHOUTHEETE, M. Dinâmica da pesquisa em Ciências Sociais. Rio de Janeiro: Livraria Francisco Alves, 1977.

CAPES/UAB. Disponível em: <http://www.uab.capes.gov.br/>. Acesso em: 15 ago. 2007.

CRUZ, D. M. O professor midiático: a formação docente para a educação a distância no ambiente virtual da videoconferência. 2001. Tese (Doutorado em Engenharia de Produção) - Programa de Pós-graduação em Engenharia de Produção, UFSC, Florianópolis, 2001.

DIMAGGIO, P.; POWELL, W. The iron cage revisited: institutional isomorphism and collective rationality in organizational fields. American Sociological Review, v. 48, n. 2, p. 147-160. 1983. 
DIMAGGIO, P.; POWELL, W. The new institutionalism in organizational analysis. Chicago: University of Chicago Press, 1992. (Introduction, p. 143-163)

ESMAN, M. J. The elements of institution building. In: EATON, J. W. (Ed.). Institution building and development: from concepts to application. London: Sage Publications, 1972. p. 21-339.

ESMAN, M. J.; BLAISE, H.C. Institution building research: the guiding concepts. Pittsburgh: Inter-University Research Program, 1966.

FÉTIZON, B. A. M.; MINTO, C. A.. Ensino a distância: equívocos, legislação e defesa da formação presencial. Universidade e Sociedade, n. 39, p. 93-105, fev. 2007.

HAIR, J. F., Jr. Fundamentos de método de pesquisa em administração. Porto Alegre: Bookman, 2005.

IBGE - Instituto Brasileiro de Geografia e Estatística. 2009. Disponível em: <http://www.ibge.gov.br> Acesso em: 15 maio 2009.

MACHADO-DA-SILVA, C.; GONÇALVES, S. A. Handbook de estudos organizacionais: modelos de análise e novas questões em estudos organizacionais. São Paulo: Atlas, 1999. (v. 1, Nota técnica: a Teoria Institucional, p. 220-226)

MAGALHÃES, J. P. Tecendo nexos: história das instituições educativas. Bragança Paulista: Editora Universitária São Francisco, 2004.

MALHOTRA, N. K. Pesquisa de marketing: uma orientação aplicada. Porto Alegre: Bookman, 2005.

MARTINS, G. A. Manual para elaboração de monografias. São Paulo: Editora Atlas, 1992.

MEYER, J.; ROWAN, B. Institutionalized organizations: formal structure as myth and ceremony. In: W. W. POWELL; P. J. DIMAGGIO (Ed.). The new institutionalism in organizational analysis. Chicago: The University of Chicago Press, 1991. p. 41-62. 
MENELAU, S. et al. E-Learning como alternativa de ensino superior: estudo de caso no curso de graduação em Administração (UFRN). Revista de Negócios, n. 13, p. $37-47,2008$.

NUNES, I. B. O que é educação à distância: noções de educação à distância. Revista Educação a Distância, v. 4, n. 5, p. 7-25, abr. 1994.

NUNES, C.; TEIXEIRA, A. A universidade de ontem e de hoje. Rio de Janeiro: EDUERJ, 1998.

POWELL, W. The new institutionalism. Thousand Oaks: Sage Publications, 2007.

SCOTT, W. R. Institutions and organizations. Thousand Oaks, CA: Sage Publications, 1995.

TOLBERT, P. A.; ZUCKER, L. G. A institucionalização da Teoria Institucional. In: S. CLEGG, C. HARDY; W. NORD (Org.). Handbook de estudos organizacionais: modelos de análise e novas questões em estudos organizacionais. São Paulo: Atlas, 1999. v. 1, p. 196-219. 